\title{
Passado, presente e futuro na perspectiva dos planos urbanos: uma análise do papel da parte oeste no contexto da expansão urbana da metrópole do Rio de Janeiro
}

Past, present and future in the perspective of urban plans: an analysis of the western border in the context of the urban expansion of the metropolis of Rio de Janeiro

Passé, présent et futur du point de vue des plans urbains : une analyse du rôle de la partie ouest dans le contexte de l'expansion urbaine de la métropole de Rio de Janeiro

Pasado, presente y futuro desde la perspectiva de los planes urbanos: un análisis del papel de la parte occidental en el contexto de la expansión urbana de la metrópolis de Rio de Janeiro

\section{Gabriela Rebello Martins}

\section{OpenEdition} Journals

\section{Edição electrónica}

URL: http://journals.openedition.org/espacoeconomia/16452

DOI: $10.4000 /$ espacoeconomia. 16452

ISSN: 2317-7837

\section{Editora}

Núcleo de Pesquisa Espaço \& Economia

\section{Refêrencia eletrónica}

Gabriela Rebello Martins, « Passado, presente e futuro na perspectiva dos planos urbanos: uma análise do papel da parte oeste no contexto da expansão urbana da metrópole do Rio de Janeiro », Espaço e Economia [Online], 19 | 2020, posto online no dia 01 setembro 2020, consultado o 11 setembro 2020. URL : http://journals.openedition.org/espacoeconomia/16452 ; DOI : https://doi.org/ 10.4000/espacoeconomia.16452

Este documento foi criado de forma automática no dia 11 setembro 2020. 


\section{Passado, presente e futuro na perspectiva dos planos urbanos: uma análise do papel da parte oeste no contexto da expansão urbana da metrópole do Rio de Janeiro}

Past, present and future in the perspective of urban plans: an analysis of the western border in the context of the urban expansion of the metropolis of Rio de Janeiro

Passé, présent et futur du point de vue des plans urbains : une analyse du rôle de la partie ouest dans le contexte de l'expansion urbaine de la métropole de Rio de Janeiro

Pasado, presente y futuro desde la perspectiva de los planes urbanos: un análisis del papel de la parte occidental en el contexto de la expansión urbana de la metrópolis de Rio de Janeiro

Gabriela Rebello Martins

\section{Introdução}

1 Os movimentos de expansão urbana em direção ao oeste metropolitano fluminense estiveram, ao longo do tempo, combinados com uma sucessão de planos urbanos elaborados para o município do Rio de Janeiro e sua área metropolitana. Neste sentido, o espaço definido neste trabalho como Oeste Metropolitano Fluminense versa sobre o conjunto de municípios que estão localizados na parte mais ocidental da baía de Guanabara juntamente com a zona oeste do município do Rio de Janeiro. Na sua parte extrema, estão incluídas as cidades de Seropédica, Japeri, Itaguaí, Queimados e Japeri; 
este espaço pode ser entendido como o mais diretamente influenciado pelas atividades industriais presentes do entorno da baía de Sepetiba, mais precisamente no eixo Itaguaí - Santa Cruz, conforme a definição proposta por Leandro Oliveira (2015):

Intitulamos esta região econômica formada por Itaguaí, Japeri, Queimados, Paracambi e Seropédica de Região Logístico-Industrial do Extremo Oeste Metropolitano Fluminense; esta região econômica tem sido palco de uma verdadeira revolução industrial extemporânea, pois emergem nas cidades que a compõe novos vetores produtivos - em especial, do ramo industrial e logístico -, e novas formas urbanas, com o gradual rompimento da estética rural até então predominante por meio de um verdadeiro processo de reestruturação territorial-produtiva (OLIVEIRA, 2015, p.3).

3 A importância de analisar o entorno da baía de Sepetiba deve-se ao fato de que é possível qualifica-lo na atualidade como um dos espaços mais dinâmicos da metrópole do Rio de Janeiro. Isto porque as atividades rurais predominavam no Extremo Oeste Metropolitano Fluminense até meados do século XX. Agregando a Zona Oeste do Rio de Janeiro, esta parte oeste se apresenta como uma das principais áreas de comércio e serviços da metrópole, concentrando um amplo número de grandes projetos industriais e portuários que deram origem a diversos estabelecimentos de apoio. Este espaço também vivencia um intenso crescimento populacional em decorrência da disponibilidade de terrenos a preços baixos e de loteamentos irregulares designados a autoconstrução de habitação. Esses fatores combinados, resultaram em profundas transformações na metrópole fluminense, favorecendo a análise sobre a produção do espaço nos extremos das áreas metropolitanas.

4 É importante destacar que esse trabalho faz parte da pesquisa em andamento de doutorado no Programa de Pós-graduação em Geografia da Universidade Federal Fluminense, na qual pretendo analisar os distintos fatores que orientam a expansão da urbanização para o entorno da baía de Sepetiba, tentando compreender, em termos mais abrangentes, o seu papel na lógica de produção do espaço do Rio de Janeiro.

5 No presente artigo, o objetivo é compreender o papel da parte oeste da região metropolitana fluminense no contexto da expansão urbana da metrópole do Rio de Janeiro através da análise dos planos urbanos que foram elaborados entre os anos de 1930 e 2018. A opção metodológica pela análise dos planos urbanos nesta fase da pesquisa deve-se ao fato de eles expressam as expectativas do Estado para o espaço, enquanto agente responsável pelo planejamento urbano e como braço do capital na busca pela sua reprodução ampliada. Neste sentido, mais a Zona Oeste do Rio de Janeiro também deve ser incluída na análise, no entendimento de se tratar de uma verdadeira leitura do Oeste Metropolitano do Rio de Janeiro.

6 Assim, serão analisados o Plano Agache (1930), Plano Doxiadis (1967), o PUB Rio (1977), os Planos Diretores da Cidade do Rio de Janeiro (1992 e 2011) e o Modelar a Metrópole (2018). Tratam-se de planos desenvolvidos em diferentes contextos sociais, políticos, econômicos e ideológicos, e que permitem entender quais foram as funções delineadas para Extremo Oeste Metropolitano Fluminense segundo os interesses do Estado em cada época. 


\section{Indústrias, portos e expansão urbana: notas sobre a produção do espaço no entorno da baía de Sepetiba}

7 O entorno da baía de Sepetiba na atualidade se destaca pela presença de portos, indústrias pesadas e até um estaleiro e base de operações para submarinos da Marinha do Brasil. Parte desses empreendimentos foram construídos já após os anos 2000 . No entanto, este espaço convive com grandes projetos de investimento desde os anos de 1960. A partir desta década, a dinâmica de produção do espaço no Extremo Oeste Metropolitano Fluminense é marcada por profundas e aceleradas transformações ocasionadas pela intensa substituição de atividades produtivas, como agricultura e pesca, por atividades industriais, portuárias e por investimentos do setor imobiliário. Esta industrialização do entorno da baía de Sepetiba foi acompanhada da expansão do tecido urbano, ainda que precariamente incluído.

Podemos então perceber que é no extremo oeste metropolitano que a metrópole do Rio de Janeiro vai encontrando caminhos para sua urbanização, fato este que Lefebvre (1999) denomina de implosão (concentração, aglomeração) e explosão (extensão do tecido urbano) do processo de produção do espaço. De acordo com o autor, o espaço é o lócus da reprodução das relações sociais de produção:

Trata-se da produção no sentido mais amplo: produção das relações sociais e reprodução de determinadas relações. É neste sentido que o espaço inteiro torna-se da lugar da reprodução, aí incluídos o espaço urbano, os espações de lazeres, os espaços ditos educativos, os da cotidianidade etc (LEFEBVRE, 2008, p.48 e 49).

O espaço é a condição para a reprodução ampliada do capital, que neste momento, atua em escala mundial. Tendo em vista que o espaço é resultado da divisão social do trabalho, a estruturação de um sistema produtivo em escala mundial demanda a existência de grandes dimensões urbanas. Neste novo ciclo da urbanização, a metrópole contemporânea se apresenta territorialmente espraiada, conturbada e com uma densidade populacional menor que a metrópole coesa que a antecedia. Esta metrópole tende a ser policêntrica, com a criação de novas centralidades em aglomerações dispersas que envolve a implosão e explosão da cidade e a própria dinâmica de concentração-dispersão das atividades econômicas.

10 É neste contexto que se insere o Extremo Oeste Metropolitano Fluminense, cujo marco do processo de industrialização pode ser situado na instalação da Ingá Mercantil em 1962, no município de Itaguaí. A indústria de zinco foi desativada em 1996, após ser responsável por um grave acidente ambiental. No entanto, a consolidação deste espaço como o principal polo de desenvolvimento industrial da metrópole do Rio de Janeiro remete à década de 1970, quando foram construídas no município de Itaguaí a Nuclep (Nuclebrás Equipamentos Pesados - empresa estatal de produção de reatores nucleares e peças metalúrgicas de alta precisão), a Fundição Técnica Sul Americana (produtora de bens de capital para a indústria naval), a Usina Itaguaí (produtora de metais não ferrosos) e a CSN (Companhia Siderúrgica Nacional). Também nos anos de 1970, a Companhia Docas do Rio de Janeiro ficou encarregada de implantar o Porto de Itaguaí (denominado inicialmente de Porto de Sepetiba) e na área vizinha, na zona oeste do município do Rio de Janeiro, foram instituídos os distritos industriais em Santa Cruz, Paciência e Campo Grande.

11 O Porto de Itaguaí foi inaugurado no ano de 1982 como resultado dos investimentos federais em grandes projetos industriais e de infraestrutura previsto no II PND entre 
1975 e 1979. Naquele momento, o interesse era ampliar a base industrial e a inserção da economia brasileira no sistema internacional de divisão do trabalho (MATOS, 2002).

Ao longo dos anos de 1980 e 1990 os investimentos nas atividades industriais diminuíram, no entanto, o processo de urbanização de forma precária se intensificou. Nos primeiros anos do século XXI, diante de um cenário econômico favorável aos investimentos e de incentivo de políticas de isenções fiscais e de financiamento público, a instalação de grandes projetos de investimento tomou fôlego novamente. Destaca-se também a importância da Lei de Modernização dos Portos (Lei no 8.630, de 25 de fevereiro de 1993) neste processo, pois autorizou a construção de terminais portuários por empresas privadas no Brasil. Grandes corporações instalaram empreendimentos no Estado do Rio de Janeiro (MARTINS, 2013), fazendo com que esse momento ficasse conhecido como a "virada econômica do Rio de Janeiro".

13 A construção da siderúrgica TKCSA teve início 2005 e, em 2017, foi comprada pela empresa Ternium, passando a se chamar Ternium Brasil. Fazem parte do complexo industrial um porto privativo com dois terminais, um ramal ferroviário e uma usina termoelétrica. Localizados no bairro de Santa Cruz, esse empreendimento tornou-se símbolo deste novo ciclo de ocupação do entorno da baía de Sepetiba, simbolizando os planos de desenvolvimento concebidos à borda oeste da metrópole fluminense.

A instalação da Ternium Brasil foi seguida pela construção do Porto Sudeste. Trata-se de um terminal privativo situado na Ilha da Madeira, ao lado do Porto de Itaguaí, para receber navios cargueiros de grande porte (com vistas ao escoamento de minério de ferro e recebimento de carvão). Merece destaque também a instalação do Complexo Naval de Itaguaí, ainda na Ilha da Madeira. o Complexo Naval abriga o estaleiro e futura base de operações para submarinos da Marinha do Brasil. Diferentemente dos empreendimentos apresentados anteriormente que pertencem à iniciativa privada, o complexo é responsabilidade da Marinha do Brasil no âmbito do Programa de Desenvolvimento de Submarinos (PROSUB).

Neste quadro de instalação de grandes projetos de investimentos no Extremo Oeste Metropolitano Fluminense, merece destaque a construção do Arco Rodoviário Metropolitano do Rio de Janeiro, cujas obras foram licitadas em 2007 e finalizadas em 2015. A criação do Arco Metropolitano visou garantir acesso rápido entre o Complexo Petroquímico do Rio de Janeiro (Comperj) em Itaboraí, no leste metropolitano, ao Porto de Itaguaí, atravessando o polo gás-químico no município de Duque de Caxias.

Denominada por Cocco et. al. (2001) como a "fronteira do oeste metropolitano", o entorno da baía de Sepetiba tornou-se o local de instalação de conjuntos habitacionais voltados à população de baixa renda, de vilas e de loteamentos regulares e irregulares, o que ocorreu mais intensamente a partir da década de 1970 (CARDOSO, A., ARAGÃO, T. e ARAÚJO, F., 2011 e FONSECA, 2015), auxiliando no espraiamento da ocupação da mancha urbana da metrópole em direção à zona oeste. Ainda que a intensidade de crescimento urbano tenha diminuído a partir da década de 1980, o Extremo Oeste Fluminense é uma das principais fronteiras de expansão urbana da metrópole do Rio de Janeiro.

17 Neste espaço, é possível verificar grande disponibilidade de terrenos a custos menores do que os mais próximos das áreas urbanas consolidadas da metrópole e, nas últimas décadas, vem apresentando um intenso crescimento populacional e concentrando os 
lançamentos imobiliários no município do Rio de Janeiro para a classe média, com destaque, nessa borda oeste, para o bairro de Campo Grande (FONSECA, 2011).

Em paralelo aos investimentos do capital imobiliário em novas unidades habitacionais para a classe média no oeste metropolitano, a partir de 2009 foi possível identificar neste espaço uma concentração de empreendimentos do programa de habitação do governo federal Minha Casa, Minha Vida. Ao analisar os empreendimentos por faixas de renda, observou-se que os imóveis voltados as classes mais baixas (de 0 a 3 salários mínimos) também estavam centralizados na Zona Oeste, especialmente no bairro de Santa Cruz (CARDOSO, ARAGÃO e ARAÚJO, 2011).

Neste sentido, pode-se perceber que as transformações no Extremo Oeste Metropolitano Fluminense em especial, mas também na Zona Oeste do Rio de Janeiro, se inserem na lógica de produção capitalista onde, no contexto da dinâmica metropolitana, ele tem abrigado, em grande medida, o que não encontra mais espaço em seu núcleo: portos, indústrias e habitação para a população de baixa renda.

\section{O Oeste Metropolitano Fluminense através dos planos urbanos}

Iniciamos nossa análise a partir do Plano Agache, primeiro plano diretor elaborado para o município do Rio de Janeiro. Em sequência, percorremos os demais planos urbanos que o seguiram. Por fim, chegamos aos planos em vigência na atualidade: 1 Plano Diretor da Cidade do Rio de Janeiro, de 2011, válido pelos 10 anos subsequentes; e 2- Plano Diretor Modelar a Metrópole, de 2018, cuja finalidade é orientar o desenvolvimento urbano, econômico e social de toda a Região Metropolitana do Rio de Janeiro até o ano de 2040.

21 Com exceção do Modelar a Metrópole, que compreendeu os municípios pertencentes a Região Metropolitana do Rio de Janeiro em 2018, e do Plano Doxiais, que propôs uma estrutura para a cidade do Rio de Janeiro a partir de um olhar sobre a dinâmica metropolitana, todos os outros planos aqui abordados limitam suas análises ao munício do Rio de Janeiro.

É notório que o atual município do Rio de Janeiro, por sua trajetória histórica-políticaeconômica, possui uma maior maturidade no quesito planejamento urbano quando comparado aos demais munícipios do Oeste Metropolitano Fluminense. Essa característica se reflete no número de legislações, planos e políticas orientadas para este assunto. Porém, é importante destacar que a análise de planos urbanos restritos aos limites territoriais do município do Rio de Janeiro não desqualifica o exercício de entendimento da dinâmica na área do entorno da baía de Sepetiba. Mas sim, nos possibilita avaliar até que ponto a produção deste espaço se constitui como um prolongamento da ocupação do núcleo metropolitano.

Zona industrial, bairros operários, áreas agrícolas, cidades satélites e áreas verdes: o extremo oeste no primeiro plano urbano do Rio de Janeiro - Plano Agache (1930)

Cidade do Rio de Janeiro: Extensão - Remodelação - Embelezamento, ou apenas Plano Agache, foi o primeiro plano diretor elaborado pela administração pública do Rio de Janeiro objetivando o planejamento da expansão urbana em direção a um modelo de cidade ideal. Concluído em 1930, o plano abrangia toda a área do então Distrito Federal e visava dotar o Rio de Janeiro de infraestrutura necessária para o desenvolvimento do 
setor industrial. No entanto, conformou-se, sobretudo, como sendo um plano de embelezamento e remodelação da área central do município.

Como analisou Vera Rezende (1982), o plano esquematizou uma cidade baseada na espacialização das funções. Nesse caso, o zoneamento proposto tinha como objetivo definir as funcionalidades de cada elemento desse "organismo" (a cidade) distribuído no espaço. No final, cada elemento deveria se articular com os demais elementos na cidade.

25 Tendo o zoneamento como instrumento de intervenção, o plano projetou cinco zonas: a) central/comercial, b) industrial e portuária, c) residência, d) zona suburbana, e e) espaços livres. Os elementos funcionais apresentariam a espacialização ilustrada na Figura 1.

Figura : Estrutura urbana proposta pelo Plano Agache - elementos funcionais.

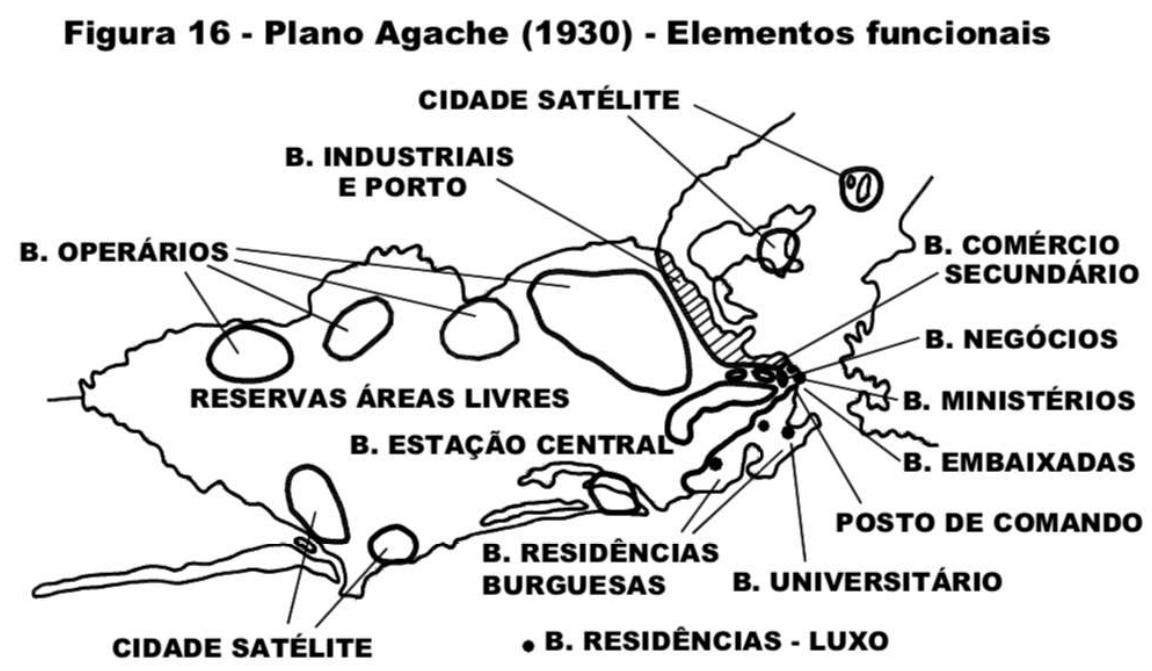

Fonte: Marília Borges (2007).

Ao analisar as proposições para a distribuição socioespacial das funções na cidade, observa-se que o Plano Agache destinou à parte oeste as áreas para indústrias, as áreas rurais e agrícolas, os bairros operários, as cidades satélites e áreas livres para recreação.

De acordo com o plano, tornar-se-ia permitido a instalação de indústrias insalubres, matadouros, agricultura intensiva e indústrias que demandam de alguma condição natural específica, como fonte de água, por exemplo. Ademais, para os bairros operários, a zona industrial e os subúrbios, o plano decretou o sistema ferroviário como principal modelo de transporte, com a finalidade de atender a demanda por acesso aos centros de emprego. Diferentemente das regiões residenciais "burguesas e abastadas", onde Agache instruiu que deveriam ser criados mecanismos legais de proibição da instalação de novas indústrias, além de incentivos à transferência das existentes para os subúrbios e para a zona industrial a ser instaurada.

Com grande preocupação sobre o crescimento da população favelada, Agache propôs a remoção total das ocupações. A solução indicada para abrigar essa população seria enviar para as vilas operárias que seriam construídas nas regiões suburbanas. 
O entorno da baía de Sepetiba como espaço privilegiado para indústrias pesadas, porto e expansão urbana: Plano Doxiadis (1967)

O Plano Doxiadis (Plano de desenvolvimento urbano a longo prazo para o Estado da Guanabara) foi elaborado em 1967, quando o atual município do Rio de Janeiro sustentava o status de Estado da Guanabara. Mais complexo que o Plano Agache, o Plano Doxiadis também se propôs a servir como um plano diretor, orientando o desenvolvimento da cidade até o ano 2000.

Compreendendo que a área urbana do Rio de Janeiro já havia excedido a do Estado da Guanabara e adentrava os municípios vizinhos, o plano propôs uma estrutura para o Estado a partir de um olhar sobre a dinâmica metropolitana. Neste sentido, indicou uma estruturação urbana para o Rio de Janeiro descentralizada e polinucleada, formada por comunidades integradas, hierarquizadas e autossuficientes (Figura 2).

Figura : Estrutura Urbana proposta pelo Plano Doxiadis

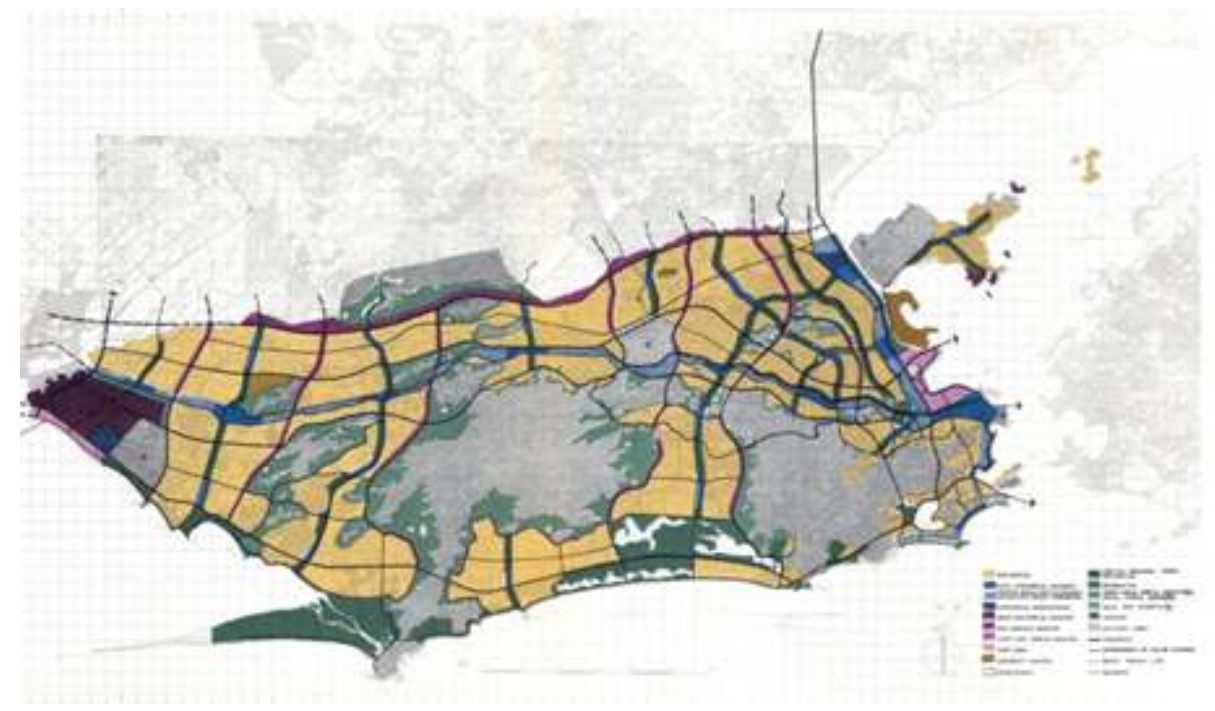

Fonte: DOXIADIS ASSOCIATES (1967)

De acordo com o Plano, o espaço que estamos chamando de Extremo Oeste Metropolitano Fluminense deveria abrigar uma área central (Santa Cruz), que teria grande importância para a formação de uma megalópole entre Rio-São Paulo, já enunciada por Doxiadis.

O Plano definiu três eixos estruturantes: 1 - norte-sul, ao longo da Avenida Brasil e Via Dutra; 2. leste-oeste, formado pela Rio-Santos e, 3. interno, ligando Jacarepaguá à avenida Brasil. $O$ eixo leste-oeste, referente a ligação entre a zona industrial de Santa Cruz e o centro da cidade, seria o principal eixo de desenvolvimento da cidade no futuro. O plano destacava o surgimento de um importante complexo industrial no bairro de Santa Cruz, no entorno da baía de Sepetiba. Naquele momento, já estava em andamento o planejamento da instalação de uma usina siderurgia da Companhia Siderúrgica da Guanabara (COSIGUA) e de uma usina termoelétrica do Vale do Paraíba (CHEVAP).

Entendendo que as indústrias presentes no Rio de Janeiro apresentavam-se altamente concentradas, o plano enfatizou a importância do desenvolvimento de uma nova área industrial na zona de Sepetiba, dedicada a indústria pesada. O plano também destacava 
a necessidade da construção de um terminal portuário na baía de Sepetiba como forma de favorecer a atividade portuária do estado, cuja expansão era considerada imprescindível, porém impraticável via Porto do Rio, engolfado na cidade e localizado próximo ao centro comercial.

Era esperado que as indústrias também estimulassem a expansão da área urbana na direção oeste. De acordo com Doxiadis, a ocupação da zona oeste do Rio de Janeiro se daria por meio da instalação de conjuntos habitacionais associados a implantação gradativa dos Distritos Industriais de Campo Grande, Palmares, Paciência e Santa Cruz. Naquele momento já era possível identificar a dinamização existente na área central do bairro de Campo Grande. Porém, havia a necessidade de que novos centros funcionais se estruturassem para que pudessem exercer a complementaridade e interdependência proposta pelo plano e atendessem, além da população local, os moradores dos municípios vizinhos de Nova Iguaçu e Itaguaí.

Com a conclusão da usina e do novo porto, haverá emprego para cerca de 32.000 pessoas. Os serviços e indústrias subsidiarias oferecerão trabalho a outras tantas pessoas. Isto significará trabalho para cerca de 60.000 pessoas e uma população local de aproximadamente 200.000 nessa nova zona industrial próxima a Santa Cruz. Esta grande comunidade necessitará de habitações e outras facilidades próprias para uma cidade autossuficiente. A COSIGUA projeta preparar partes de Santa Cruz e Sepetiba para as necessidades imediatas de moradia dos trabalhadores (DOXIADIS ASSOCIATES, 1967, parágrafo 388).

O desenvolvimento de novas áreas residenciais na zona oeste foi a forma encontrada para solucionar o grave problema habitacional enfrentado pelo Rio de Janeiro, já evidente na década de 1960. Para Doxiadis, essas novas áreas residenciais deveriam estar associadas às novas áreas de localização das indústrias, de negócios e comerciais. Além das indústrias, das habitações populares e dos centros comerciais, o extremo oeste também deveria sediar uma universidade que deveria ser criada na área central de Santa Cruz.

O extremo oeste no PUB Rio (1977): as áreas agrícolas como reservas de espaço para a expansão urbana em contexto de intenso crescimento populacional na metrópole fluminense

O Plano Urbanístico Básico da Cidade do Rio de Janeiro (PUB Rio) foi lançado em junho de 1977, dois anos após a constituição do município do Rio de Janeiro. Diferentemente dos planos que o antecederam, o PUB Rio foi elaborado por técnicos da prefeitura do Rio de Janeiro. $O$ objetivo do Plano era orientar as ações dentro do município do Rio, porém se atentando para sua condição de centro nevrálgico de uma região metropolitana em franco crescimento populacional e cuja ocupação territorial estaria condicionada pelos corredores de transporte até então existentes. $O$ contexto da cidade do Rio de Janeiro no momento da elaboração do PUB Rio era o seguinte:

A partir de 1973, com a instituição e reconhecimento da Região Metropolitana, a problemática do solo começa a ser vista de forma mais abrangente. Como polo dessa região metropolitana, a cidade continua atraindo razoável fluxo de migrantes, embora o processo tenha apresentado uma desaceleração pelo excessivo crescimento de São Paulo e a transferência da capital para Brasília. Parte dessa população migrante não consegue instalar-se no município e vai em direção à sua periferia, às cidades como São João de Meriti, Nova Iguaçu, Duque de Caxias e Nilópolis (REZENDE, 1982, p.62). 

déficit de habitação e a falta de equipamentos e serviços públicos, que não acompanharam a expansão urbana. Nesse contexto, o PUB Rio ressaltou a necessidade de uma estrutura urbana descentralizada e apresentou a divisão do município em 6 Áreas de Planejamento (AP's): AP-1, AP-2, AP-3, AP-4, AP-5 e AP-6, no qual cada área se apresentaria como uma região homogênea com características, problemas e demandas sociais próprias e que exigiriam intervenções específicas (Figura 3).

Figura : Estrutura urbana proposta pelo PUB Rio.

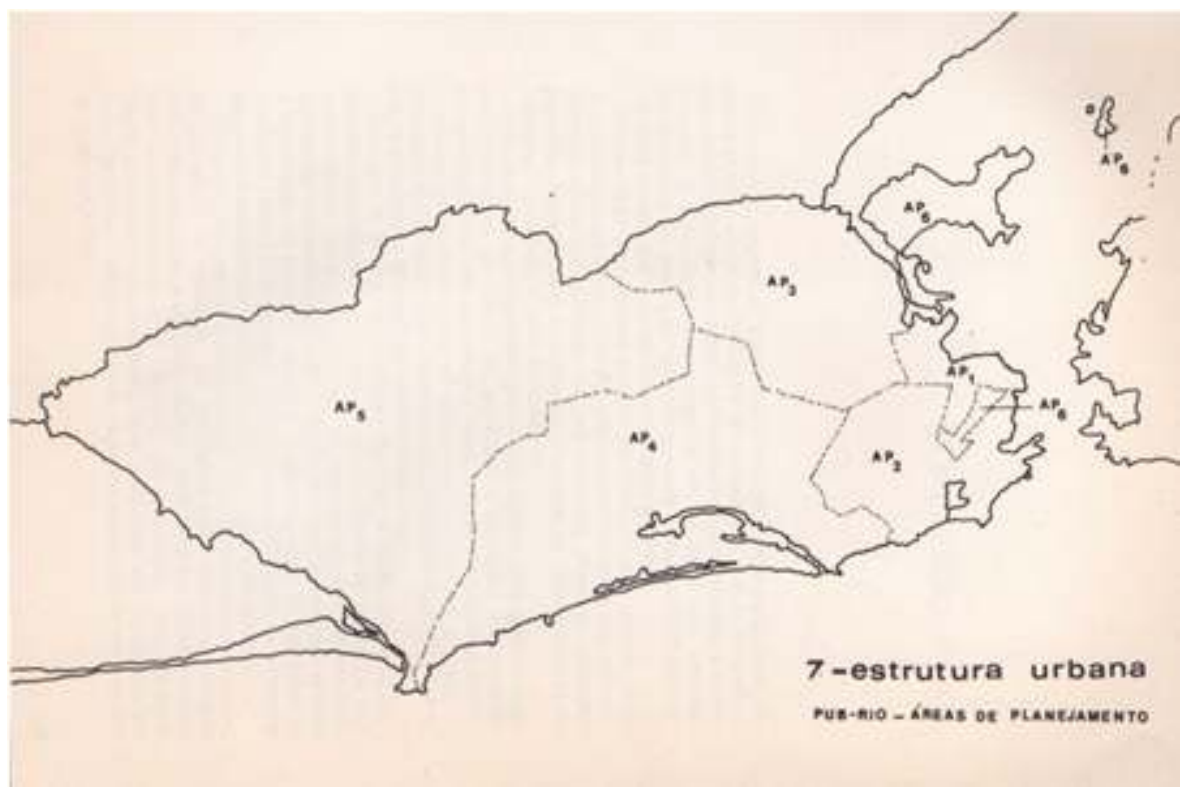

Fonte: Áreas de Planejamento. Fonte: REZENDE (1982). 
42

No contexto da AP5, as prioridades seriam: o fortalecimento das áreas centrais, que deveriam funcionar de forma complementar; a promoção a expansão urbana; o controle do parcelamento da terra, com vistas à concentração da ocupação no lugar da dispersão urbana; a promoção de infraestrutura nas áreas industriais, residenciais e nos centros funcionais; e, por fim, a preservação da reserva biológica de Guaratiba.

Ao final da caracterização física, social e econômica apresentada nos capítulos iniciais do Plano, o PUB Rio apresentou as propostas para o desenvolvimento da cidade, conforme ilustra a Figura 4.

Figura : Mapa síntese das propostas do PUB Rio.

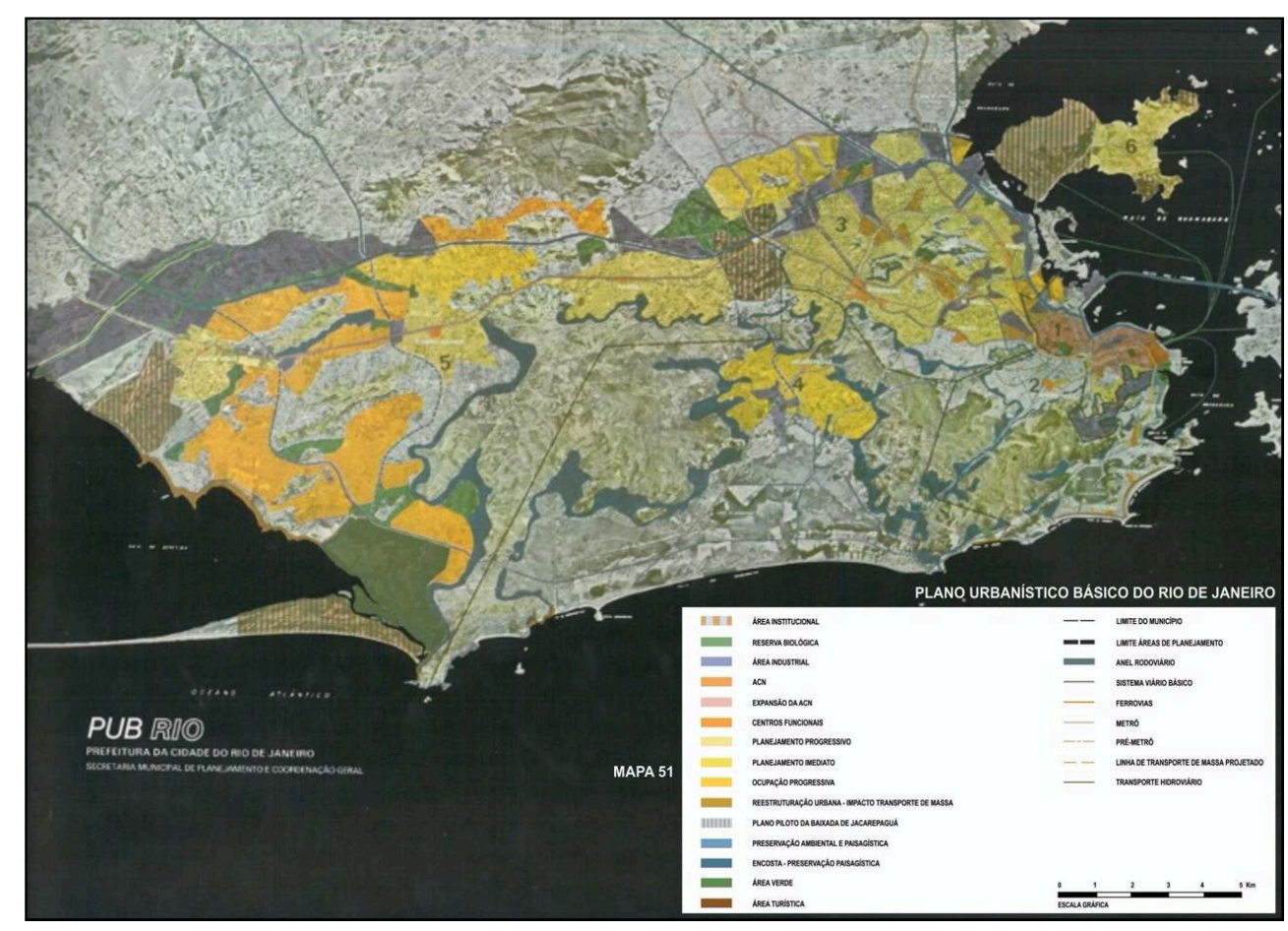

Fonte: Prefeitura da Cidade do Rio de Janeiro (1977).

É possível perceber que a maior área industrial do município se localizava no entorno da baía de Sepetiba. Ademais, áreas que deveriam ser remanejadas, centros funcionais, áreas institucionais e áreas verdes faziam parte do planejamento do Estado para este espaço.

Plano Diretor de 1992: expansão urbana para o extremo oeste associada a geração de empregos a fim de evitar os grandes deslocamentos na cidade

O Plano Diretor Decenal da Cidade do Rio de Janeiro de 1992 teve como característica principal as diretrizes voltadas às questões ambientais, principalmente referentes a expansão da cidade em direção à Zona Oeste, visando garantir a preservação ambiental diante da ocupação acelerada.

De acordo com o Plano, o território municipal ficou dividido em 3 tipos de macrozonas:

47 I - macrozonas urbanas - áreas já ocupadas;

48

II - macrozonas de expansão urbana - destinadas a ocupação, considerada necessária ao crescimento da Cidade; 
- macrozonas de restrição à ocupação urbana - áreas com condições físicas adversas à ocupação ou destinadas a ocupação agrícola ou sujeitas a proteção ambiental ou impróprias à urbanização.

O trecho da zona oeste da cidade do Rio de Janeiro que faz parte da nossa pesquisa ficou delimitada como macrozona de expansão urbana, sendo um vetor de crescimento a partir da área central da cidade:

Art. 45 - A ocupação urbana do Município consolidará os grandes vetores de crescimento do centro da Cidade para a Zona Norte - Área de Planejamento 3, para a Zona Oeste - Área de Planejamento 5 e para a região de Jacarepaguá, na Área de Planejamento 4, bem como os vetores que se irradiam a partir de centros de comércio e serviços (PREFEITURA DA CIDADE DO RIO DE JANEIRO,1992).

das macrozonas de expansão urbana, no entorno da baía de Sepetiba também foram demarcadas macrozonas de restrição à ocupação urbana como a área de Guaratiba, o Maciço da Pedra Branca e o Mendanha.

Alterando a espacialização proposta pelo PUB Rio de 6 AP's, o Plano Diretor de 1992 ordenou o Rio de Janeiro em 5 AP's, formadas pelo agrupamento de 34 Regiões Administrativas (RA's) e estas por grupos de bairros (Figura 5).

Figura : Divisão do município do Rio de Janeiro em Áreas de Planejamento e Regiões Administrativas segundo o Plano Diretor de 1992.

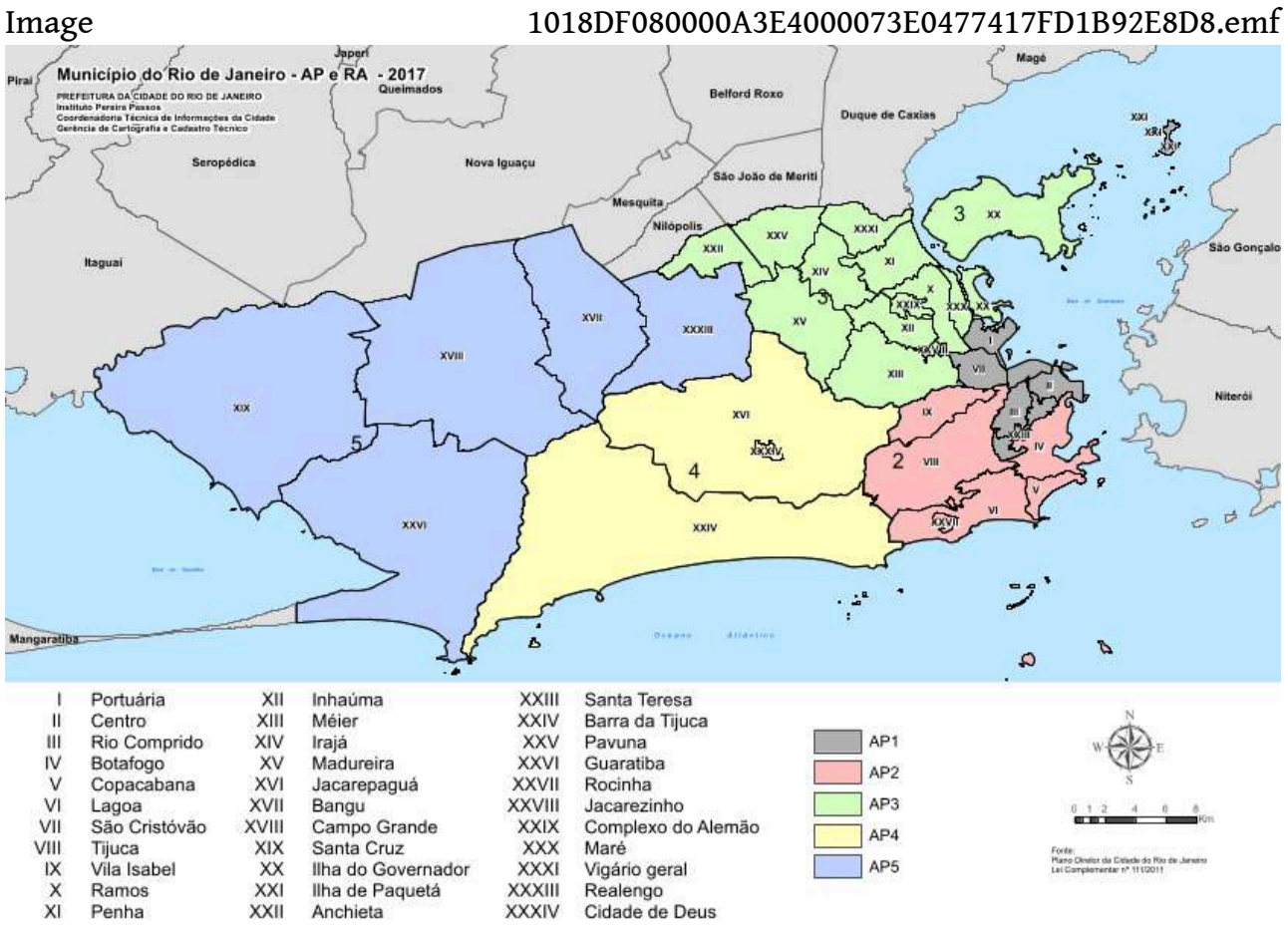

Fonte: DATARIO (2017)

Dentre as diretrizes de uso e ocupação do solo para a AP 5, estavam a proteção das áreas de atividades agrícolas de modo a evitar a extensão da malha urbana e, posteriormente, o estímulo ao desenvolvimento turístico em Guaratiba, Sepetiba, Pedra de Guaratiba, Barra de Guaratiba e no Pico da Pedra Branca, que são atividades relacionadas a manutenção do ambiente natural. No entanto, também era recomendado o estímulo a ocupação urbana na faixa de território compreendida entre o lado ímpar da Avenida 
Brasil e a linha ferroviária, ainda que sem o incentivo à construção de conjuntos habitacionais de grande porte como em outrora.

Igualmente sobre os grandes conjuntos habitacionais, o Plano estabeleceu que deveriam ser definidos parâmetros de ocupação e formas de transição das áreas contíguas a estes empreendimentos a fim de integrá-los à malha urbana, indicando uma problemática existente sobre a inserção dos conjuntos no espaço urbano.

O Plano Diretor também destacou como orientação para o uso e ocupação do solo para a AP 5 o incentivo à instalação de atividades geradoras de emprego, objetivando reduzir os deslocamentos e à consolidação das áreas destinadas ao uso industrial, incluindo atividades potencialmente poluidoras.

Pano Diretor de 2011: sem infraestrutura urbana, o extremo oeste faz parte da macrozona de ocupação assistida

Após quase 20 anos da elaboração do Plano Diretor de 1992, cuja revisão deveria ser decenal, em 2011 foi instituído o Plano Diretor de Desenvolvimento Urbano Sustentável do Município do Rio de Janeiro. O Plano Diretor de 2011 está em vigor nos dias atuais e, portanto, estabelece as diretrizes e linhas de ação para a política urbana do Rio de Janeiro.

Para fins de ordenamento territorial, a cidade passou a ser dividida em quatro macrozonas de ocupação (Figura 6):

i. Macrozona de Ocupação Controlada - zona com restrição a ocupação (Zona Sul e parte do Centro da cidade);

ii. Macrozona de Ocupação Incentivada -áreas já dotadas de infraestrutura, mas que sofreram esvaziamento e deterioração cuja ocupação é incentivada.

iii. Macrozona de ocupação Condicionada - a ocupação deveria ser associada a investimentos em infraestrutura.

iv. Macrozona de Ocupação Assistida - nesta área, o Estado seria o responsável por incentivar sua ocupação e o consequente incremento das atividades econômicas, dotando o local de infraestrutura, serviços urbanos e provisão de moradias e zelando pela proteção ambiental. 
Figura : Macrozonas propostas pelo Plano Diretor do Rio de Janeiro.

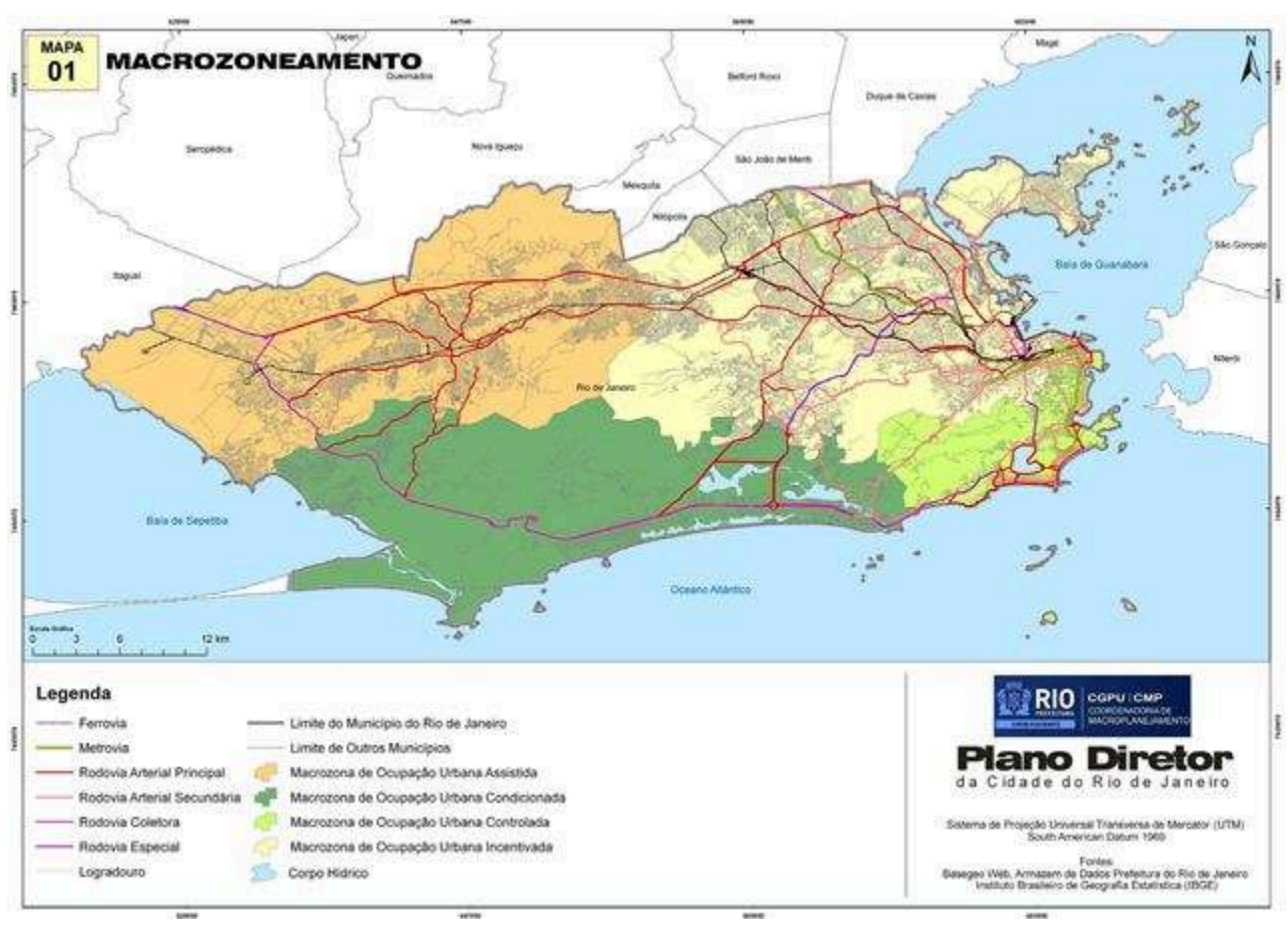

Fonte: PREFEITURA DA CIDADE DO RIO DE JANEIRO (2011).

O macrozoneamento seria o reconhecimento das diferenciações do espaço e a busca pelo estabelecimento de princípios orientadores do controle do processo de adensamento e de expansão da cidade. Conforme pode ser visto na Figura 6, a parte oeste foi considerada como área de ocupação assistida, que poderia ser caracterizada pelo crescimento populacional acelerado, baixa renda média mensal, carência de proteção ambiental, de infraestrutura, de transportes, de serviços urbanos e de moradias. Neste contexto, a macrozona classificada como assistida é:

onde o adensamento populacional, o incremento das atividades econômicas e a instalação de complexos econômicos deverão ser acompanhados por investimentos públicos em infraestrutura e por medidas de proteção ao meio ambiente e à atividade agrícola (PREFEITURA DA CIDADE DO RIO DE JANEIRO, 2011, art.32, IV).

Neste contexto, na seção II, artigo 33, sobre os vetores de Crescimento da Cidade, o Plano Diretor determinou que a ocupação urbana no Município se orientaria via ocupação de vazios urbanos que incluem Macrozonas de Ocupação Assistida, especialmente na faixa territorial compreendida entre a Av. Brasil e o leito da estrada de ferro, na Zona Oeste, e a região da Zona Portuária;

O Plano ainda definiu que nos bairros de Santa Cruz e de Campo Grande, os parâmetros urbanísticos, as normas de controle ambiental e as condições de infraestrutura seriam voltadas à instalação de indústrias e equipamentos de grande porte, considerada a necessidade de incremento do uso residencial e o fortalecimento das atividades econômicas desta natureza nesta região. de Ocupação Assistida, assim como na Macrozona Incentivada, deveriam ser estabelecidas normas visando a produção de unidades novas para moradia popular e a 
regularização de unidades existentes, sendo possível a aplicação de padrões urbanísticos mais flexíveis.

E o futuro? Como o Modelar a Metrópole projeta o Oeste Metropolitano até 2040

A Câmara Metropolitana de Integração Governamental foi instituída pelo Governo do Estado do Rio de Janeiro no ano de 2014 com intuito de desenvolver ações de planejamento urbano e gestão na escala metropolitana. Diante deste objetivo, a Câmara Metropolitana organizou o Modelar a Metrópole - Plano Estratégico de Desenvolvimento Urbano Integrado da Região Metropolitana do Rio de Janeiro. O Plano, elaborado por um consórcio formado por empresas privadas de arquitetura, foi publicado em 2018 sugerindo um conjunto de cenários, estratégias e instrumentos que pudessem orientar as decisões governamentais na escala metropolitana até o ano de 2040.

A "Proposta de Reconfiguração Espacial" consistiu no fortalecimento das centralidades visando a desconcentração espacial de atividades e pessoas. No Oeste Metropolitano Fluminense, o bairro de Campo Grande apareceu como um subcentro de grande importância, assim como a conexão deste subcentro com Santa Cruz e Itaguaí. Devido ao seu complexo portuário, sua zona industrial e a presença do Arco Metropolitano, Itaguaí também mereceu destaque quando considerada sua relevância para o desenvolvimento do Rio de Janeiro.

Observando as propostas apresentadas para a mobilidade metropolitana, o Plano chama a atenção para o eixo oeste da metrópole, justificada pelas atividades logísticas e industriais. O Arco Metropolitano recebe a categoria de "eixo logístico" (p.682) e, por essa condição, o plano incentiva "a criação de um conjunto de áreas retroportuárias, de indústrias e de logística na região de Seropédica, Queimados e Japeri” (p.682).

As atividades econômicas e a dinâmica populacional em curso no oeste metropolitano seriam, de acordo com o Plano, características que poderiam auxiliar na mudança de circulação e ocupação da metrópole fluminense:

o Porto de Itaguaí e as áreas industriais localizadas nesse município e no extremo oeste do município do Rio de Janeiro, bem como o conjunto de áreas industriais em Queimados, Seropédica e Paracambi criam condições para uma alteração na dinâmica dos deslocamentos e da ocupação urbana na Região Metropolitana, que já se encontra em curso (p.682).

67 Considerando o diagnóstico elaborado para a Região Metropolitana do Rio de Janeiro (RMRJ) e as perspectivas para este espaço em um horizonte de pouco mais de 20 anos, o plano apresentou uma proposta de Macrozoneamento Metropolitano. No extremo oeste da metrópole, destacavam-se a Macrozona de Qualificação, alguns espaços indicados como Macrozona de Coesão Sócio Territorial e Macrozona de Atividade Econômica (Figura 7). 
Figura : Macrozoneamento Metropolitano de acordo com o Modelar à Metrópole.

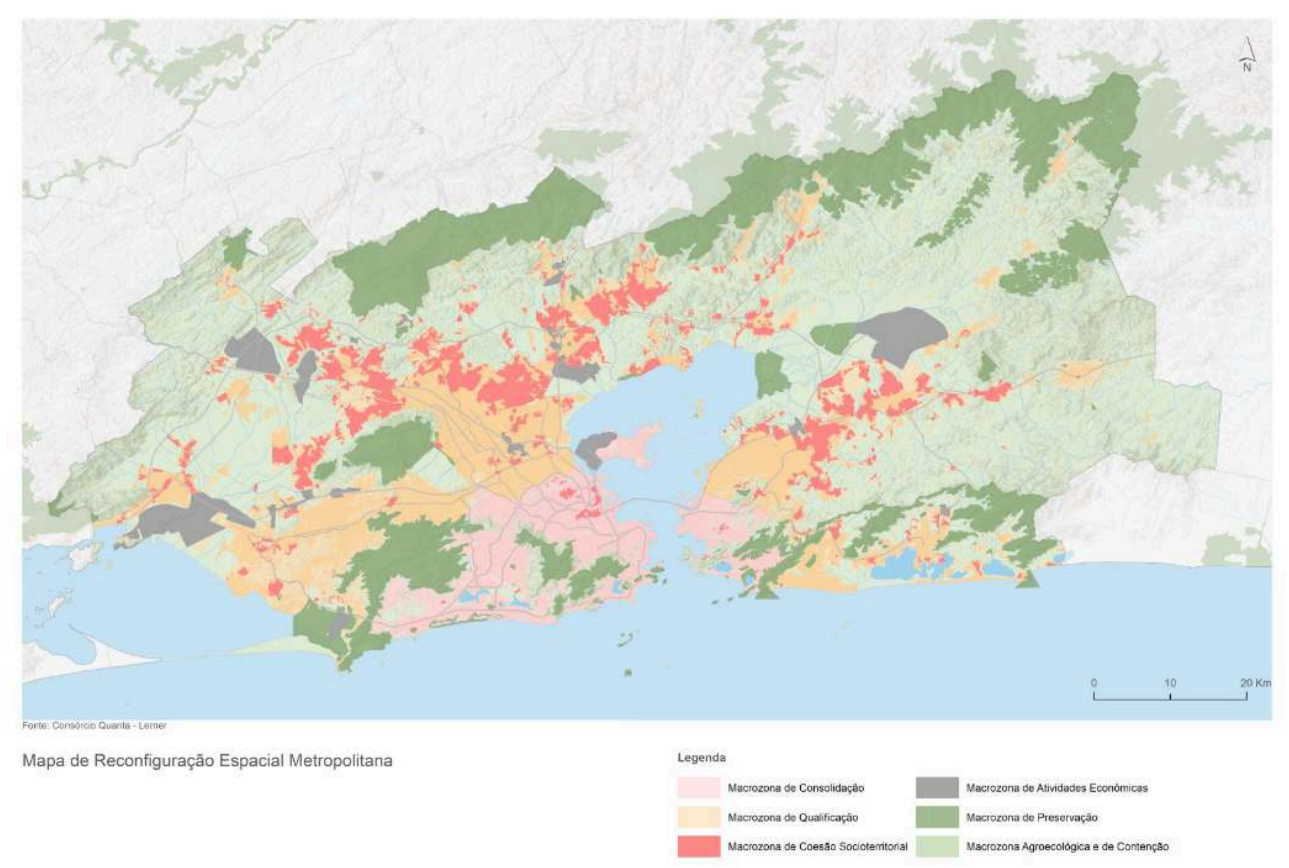

Fonte: CÂMARA METROPOLITANA DO RIO DE JANEIRO, 2018.

As áreas definidas como Macrozona de Coesão Territorial foram as áreas consideradas mais vulneráveis na RMRJ. Estas macrozonas "deverão contar com políticas públicas incluindo a implantação de infraestrutura urbana, equipamentos e serviços sociais que alavanquem a integração desses assentamentos às áreas urbanas formais e mais qualificadas existentes no seu entorno" (p.695).

Já a Macrozona de Atividade Econômica incorporou a área do complexo portuário e industrial de Itaguaí, as áreas de interesse industrial de Seropédica, Japeri, Queimados, Nova Iguaçu e Duque de Caxias, localizadas junto ao Arco Metropolitano e, por fim, o Comperj em Itaboraí. Segundo o plano, estas áreas apresentavam usos industriais e instalações de logística de grande interesse para a região metropolitana e, através delas, seria possível "reduzir a dependência da Região Metropolitana em relação à cidade do Rio de Janeiro, ao aumentar a dinâmica econômica em novas áreas" (p.695).

O Modelar a Metrópole ainda definiu "Zonas de Interesse Metropolitano", como forma de destacar "o interesse metropolitano no desenvolvimento de ações em determinadas porções territoriais" (p.696). Nesta zona, o plano incluiu, mais uma vez, o entorno do Arco Metropolitano com vistas ao desenvolvimento industrial e de logística de apoio ao Porto de Sepetiba e ao COMPERJ. Também incluiu o entorno da Avenida Brasil e da Rodovia Mario Covas, de Itaguaí até Manilha, onde podem coexistir atividades de serviço, de logística e industriais, além das áreas portuárias, retroportuárias, industriais e de logística no município de Itaguaí e na região oeste do Rio de Janeiro.

Após apresentar a proposta de um macrozoneamento e de definir as áreas de interesse, o Modelar a Metrópole apresentou o projeto de Reconfiguração Espacial Metropolitana conforme ilustra a Figura 8. 


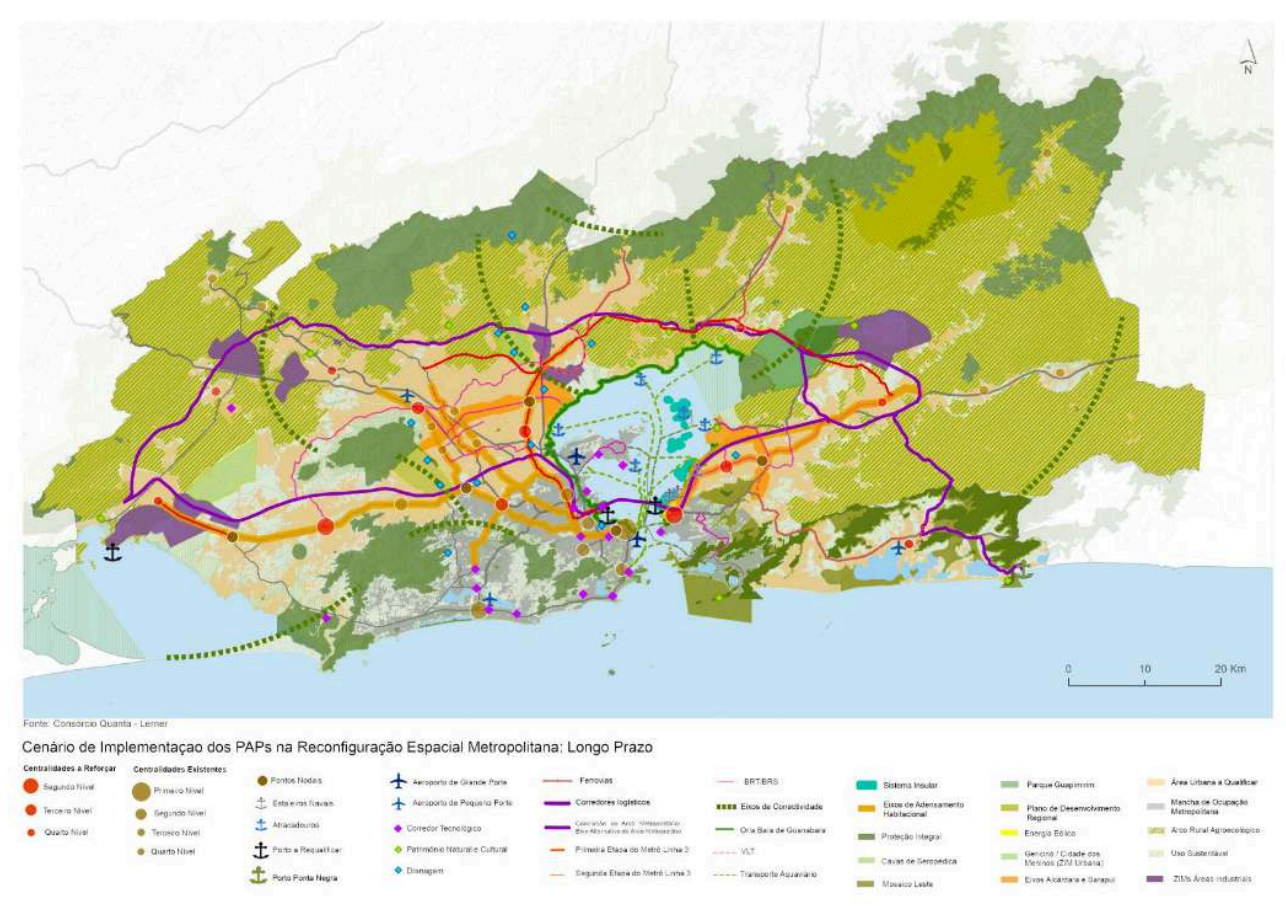

Fonte: CÂMARA METROPOLITANA DO RIO DE JANEIRO, 2018.

Como pode ser visto, o plano espera que até 2040 o Extremo Oeste Metropolitano Fluminense seja composto por áreas industriais e corredores logísticos, áreas urbanas passíveis de qualificação com eixos de adensamento habitacional e pelo cinturão rural e áreas de proteção ambiental. No mais, indica o fortalecimento das centralidades já existentes.

\section{Considerações Finais}

73 A discussão sobre a ocupação da parte oeste metropolitana do Rio de Janeiro esteve presente nos diferentes momentos em que o Estado compeliu esforços para planejar a ocupação da metrópole do Rio de Janeiro. Produtos desse planejamento, os planos urbanos permitiram analisar a relação entre transformações na lógica de produção do espaço do entorno da baía de Sepetiba e o desenvolvimento de uma dinâmica metropolitana no Rio de Janeiro e de reprodução ampliada do capital.

Uma vez que no momento da elaboração do Plano Agache o extremo oeste se configurava como um espaço distante da urbe, este ficou delegado às indústrias insalubres, às atividades que demandassem áreas livres e recursos naturais e até à população que habitava as favelas das áreas centrais, ou seja, atividades que não eram convenientes no núcleo.

75 A chamada vocação industrial/portuária deste recorte regional já estava registrada no Plano Doxiadis. No plano, a expansão da urbanização da cidade se daria no eixo lesteoeste, porém, associada às atividades industriais anunciadas para este espaço. Essa expansão teria grande valor para o desenvolvimento econômico do Rio de Janeiro.

Na década de 1970, em um contexto em que o tecido urbano da metrópole se expandia para além dos limites municipais e que as atividades industriais já eram uma realidade 
no extremo oeste da cidade, o PUB Rio enfatizou a importância do controle da ocupação deste espaço, da promoção de infraestrutura e do fortalecimento dos centros no extremo oeste.

Então, em 1992, de acordo com o Plano Diretor, esperava-se que a Zona Oeste conjugasse [a] preservação de espaços produtores de hortifrutigranjeiro, agroindustriais e de pequena criação animal; [b] o turismo na Baía de Sepetiba e no maciço do Mendanha; [c] acolhesse a população crescente do Rio de Janeiro, mas não mais sob a forma de conjuntos habitacionais; [d] desenvolvesse postos de trabalho a fim de absorver a população trabalhadora e evitasse o deslocamento diário para a área central da cidade; e, [e] atividades industriais altamente poluidoras e impactantes para a saúde da população vizinha.

Ainda em vigor, o Plano Diretor de 2011 classificou o extremo oeste da cidade do Rio de Janeiro como uma Macrozona de Ocupação Assistida, cujo Estado é o responsável por incentivar e orientar sua ocupação. Além de servir à expansão urbana e do capital, este também deve se manter como espaço das atividades rurais e de áreas naturais protegidas.

Dentre os planos analisados, o Modelar à Metrópole é o mais recente, o único de escala metropolitana e também o que aponta horizontes. Neste plano, o Extremo Oeste Metropolitano Fluminense possui bastante relevância para o desenvolvimento social e econômico da metrópole do Rio de Janeiro. Mais uma vez, a importância desse espaço deve-se às atividades portuárias e industriais, consideradas capazes de dinamizar economicamente esse espaço a ponto de reduzir a dependência do entorno metropolitano em relação ao núcleo. Por outro lado, o Plano também destacou a demanda por infraestrutura urbana e equipamentos e serviços sociais.

Pode-se perceber que a parte oeste da cidade do Rio de Janeiro já há bastante tempo possui lugar nos planos urbanos como área de indústria pesada da metrópole, com grande importância para a dinâmica econômica. No entanto, também foi possível notar que todos os planos destacaram a necessidade de dotar este espaço de infraestrutura urbana e social como reflexo de sua ocupação recente e acelerada, sugerindo um espaço de urbanização precária. Neste verdadeiro Oeste Metropolitano, conjugando o Extremo Oeste com a Zona Oeste da cidade do Rio de Janeiro, a industrialização em curso - que já não é tão recente, mas que ganhou novo fôlego na virada do século XXI - não tem reverberado em ganhos sociais para o seu entorno.

\section{BIBLIOGRAFIA}

AGACHE, Agache. Cidade do Rio de Janeiro: Extensão-Remodelação-Embellezamento. Paris: Foyer Brésilien, 1930. Disponível em http://planourbano.rio.rj.gov.br, acesso em 10 de maio de 2019.

BORGES, Marília Vicente. O zoneamento na cidade do Rio de Janeiro: gênese, evolução e aplicação. Rio de Janeiro, Dissertação de Mestrado. Instituto de Pesquisa e Planejamento Urbano, Universidade Federal do Rio de Janeiro, 2007. 
BRASIL. Lei nº 8.630, de 25 de fevereiro de 1993. Lei de Modernização dos Portos. Dispõe sobre o regime jurídico da exploração dos portos organizados e das instalações portuárias e dá outras providências. Informações extraídas online de: <http://www.jusbrasil.com.br/legislacao/103547/ lei-de-modernizacao-dos-portos-lei-8630-93>. Acesso em 12 de janeiro de 2018.

CÂMARA METROPOLITANA DO RIO DE JANEIRO. Modelar à Metropole - Plano Estratégico de Desenvolvimento Urbano Integrado da Região Metropolitana do Rio de Janeiro. 2018. Disponível em https://www.modelarametropole.com.br/documentos/\#documentos-produtos. Acesso em: 20 de abril de 2019.

CARDOSO, Adauto Lucio; ARAGÃO, Thêmis Amorim. ARAÚJO, Flávia de Sousa. Habitação de Interesse Social: Política ou Mercado? Reflexos sobre a construção do espaço metropolitano. In: XIV Encontro Nacional da ANPUR, 2011, Rio de Janeiro. Anais do XIV Encontro Nacional da ANPUR, 2011.

COCCO, Giuseppe; SILVA, Gerardo; PAIVA, Cecília; MONIÉ, Frédéric.; BORGES, Silvia; GALVÃO, Alexander. A cidade estratégica: novas e velhas práticas no planejamento do Rio de Janeiro: a impostura do Porto de Sepetiba. Rio de Janeiro: DP\&A, 2001.

DATARIO. Mapa de divisão do Município do Rio de Janeiro em Áreas de Planejamento e Regiões Administrativas - 2017. Disponível em: http://www.data.rio/datasets/

3f105a10dcf7475eae69b2514b9d6262 Acesso em 24 de novembro de 2019.

DOXIADIS ASSOCIATES. Guanabara, um plano para desenvolvimento urbano. Plano Doxiadis. Tradução CEPE 1. Secretaria de Governo. Rio de Janeiro, v. 1-2, 1967.

FONSECA, Priscilla Rodrigues. A (re)configuração do espaço do bairro de campo grande no Rio de Janeiro: o Desenvolvimento do Subcentro Comercial e a Ação da Indústria Imobiliária. Niterói, Trabalho de Conclusão de Curso (Bacharelado em Geografia). Universidade Federal Fluminense, 2011.

FONSECA, Priscilla Rodrigues. 0 impacto da localização diferenciada dos investimentos na estruturação socioespacial da cidade: uma análise multiescalar do bairro de Campo Grande, Rio de Janeiro. Rio de Janeiro, Dissertação de Mestrado. Instituto de Pesquisa e Planejamento Urbano, Universidade Federal do Rio de Janeiro, 2015.

LEFEBVRE, Henri. A revolução urbana. Belo Horizonte: Editora UFMG, 1999.

LEFEBVRE, Henri. Espaço e política. Belo Horizonte: Ed. da UFMG, 2008.

MARTINS, Gabriela Rebello. (2013). Disputas por legitimidade em torno dos grandes projetos de investimento: Uma análise do processo de criação do Superporto do Açu em São João da Barra - RJ. Dissertação (Mestrado em Planejamento Urbano e Regional) - Programa de Pós-Graduação em Planejamento Urbano e Regional, Universidade Federal do Rio de Janeiro, Rio de Janeiro.

MATOS, Patrícia de Oliveira. Análise dos planos de desenvolvimentos elaborados no Brasil após o III PND. Piracicaba. Dissertação (Mestrado em Economia Aplicada) - Escola Superior de Agricultura Luiz de Queiroz. Unidade da USP: 2002.

OLIVEIRA, Leandro Dias de. A emersão da região logístico-industrial do Extremo Oeste Metropolitano fluminense: reflexões sobre o processo contemporâneo de reestruturação territorial-produtiva. Espaço e Economia [Online], 7 | 2015, posto online no dia 12 abril 2016, consultado o 10 novembro 2019. URL : http://journals.openedition.org/espacoeconomia/1814 ; DOI : $10.4000 /$ espacoeconomia.1814

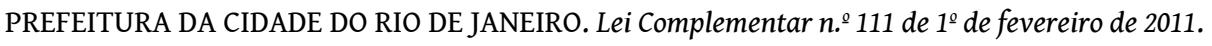
Dispõe sobre a Política Urbana e Ambiental do Município, institui o Plano Diretor de 
Desenvolvimento Urbano Sustentável do Município do Rio de Janeiro e dá outras providências, 2011.

PREFEITURA DA CIDADE DO RIO DE JANEIRO. Lei Complementar no 16 de 04 de junho de 1992. Dispõe sobre a política urbana do município, institui o Plano Diretor Decenal da Cidade do Rio de Janeiro e dá outras providências, 1992.

PREFEITURA DA CIDADE DO RIO DE JANEIRO. Plano Urbanístico Básico da Cidade do Rio de Janeiro (PUB Rio), 1977.

REZENDE, Vera. Planejamento urbano e ideologia: quatros Planos para a Cidade do Rio de Janeiro. Rio de Janeiro: Editora Civilização Brasileira S.A., 1982.

\section{RESUMOS}

Nos primeiros anos do século XXI, novos projetos de investimento foram instalados no extremo oeste metropolitano do Rio de Janeiro, que desde 1960 hospeda empreendimentos industriais e de logística. Essa "prosperidade industrial" tem sido acompanhada pelo crescimento dos conjuntos habitacionais, dos loteamentos informais e do número de moradores. Essa condição é fruto de uma acelerada inserção do entorno da Baía de Sepetiba na dinâmica metropolitana a partir da segunda metade do século XX, quando teve início a substituição das atividades rurais. Nesse contexto, o presente artigo tem como objetivo compreender o papel do extremo oeste diante da expansão urbana da metrópole do Rio de Janeiro através da análise dos planos urbanos desenvolvidos pelo Estado entre os anos de 1930 e 2018. Ao final, foi possível perceber o grande destaque dado pelos planos às atividades industriais para o desenvolvimento não só do entorno da Baía de Sepetiba, como do Rio de Janeiro, e também a necessidade de dotar este espaço de infraestrutura, indicando que a industrialização em curso na baía de Sepetiba, não tão recente, mas que ganhou novo fôlego na virada do século XXI, não tem reverberado em ganhos para o seu entorno.

In the first years of the 21st century, new investment projects were implemented in the westernmost metropolitan part of Rio de Janeiro, which has been hosting logistics and industrial enterprises since 1960. This "industrial property" has been followed by the growth of spaces dedicated to low-cost housing, informal settlement parcels and population. This condition results from the accelerated insertion of the surroundings of Sepetiba Bay into the metropolitan dynamics on the second half of XX century, when the substitution of rural activities started to take place. In this context, this paper aims to understand the role of Rio de Janeiro's Extreme Metropolitan West in face of the urban expansion of the metropolis, through the analysis of the urban plans developed by the State between 1930 and 2018. Based on this study, it was possible to notice the great emphasis given by the plans to the industrial activities in order to develop not only the surroundings of the Sepetiba Bay, but also of Rio de Janeiro. In addition, the plans also show a necessity to endow this space with infrastructure, pointing out that the ongoing industrialization on Sepetiba Bay, not so recent, but with a new strength in the turn of the $21^{\text {st }}$ century, do not reverberate in gains to its surroundings.

Au début du XXIème siècle, de nouveaux projets d'investissement ont été installés dans l'extrême ouest métropolitain du Rio de Janeiro, qui accueille depuis 1960 des entreprises industrielles et logistiques. Cette «prospérité industrielle » s'est accompagnée de la croissance des lotissements, des lotissements informels et du nombre de résidents. Cette condition est le résultat d'une insertion accélérée des abords de la Baía de Sepetiba dans la dynamique métropolitaine de la seconde moitié du XXème siècle, lorsque le remplacement des activités rurales a commencé. Dans 
ce contexte, cet article vise à comprendre le rôle de l'extrême ouest face à l'expansion urbaine de la métropole du Rio de Janeiro à travers l'analyse des plans urbains élaborés par l'État entre les années 1930 et 2018. À la fin, il a été possible de percevoir l'accent mis par les plans d'activités industrielles pour le développement non seulement des environs de la Baía de Sepetiba, mais aussi de Rio de Janeiro, et aussi la nécessité de doter cet espace d'infrastructures, indiquant que l'industrialisation en cours dans la Baía de Sepetiba, pas si récente, mais qui a pris un nouvel élan au tournant du XXIème siècle, il n'a pas eu de retombées positives pour son environnement.

Extrême Ouest Métropolitan du Rio de Janeiro, Expansion urbaine, Baía de Sepetiba, Plans urbains, Grands projets d'investissement.

\title{
ÍNDICE
}

Keywords: Metropolitan Westernmost part of Rio de Janeiro, Urban expansion, Sepetiba Bay, Urban plans, Large investment projects

Palavras-chave: Extremo Oeste Metropolitano Fluminense, Expansão urbana, Baía de Sepetiba, Planos urbanos, Grandes projetos de investimento.

Palabras claves: Extremo Oeste Metropolitano de Rio de Janeiro, Expansión urbana, Bahía de Sepetiba, Planes urbanos, Grandes proyectos de inversión.

\author{
AUTOR \\ GABRIELA REBELLO MARTINS \\ Doutoranda em Geografia pelo Programa de Pós-Graduação em Geografia da Universidade \\ Federal Fluminense (UFF), Mestre em Planejamento Urbano e Regional pelo Instituto de Pesquisa \\ e Planejamento Urbano e Regional da Universidade Federal do Rio de Janeiro (IPPUR-UFRJ), \\ Especialista em Política e Planejamento Urbano também pelo IPPUR-UFRJ, Bacharel e Licenciada \\ em Geografia pela UFF. E-mail: gabrielarebello@gmail.com.
}

